\title{
Comparison of Experienced vs. Novice Teachers in Cognitive Reflection and Rationality
}

\author{
Vladimíra Čavojová, Marek Jurkovič \\ Institute of Experimental Psychology \\ Center of Social and Psychological Sciences, Slovak Academy of Sciences
}

\begin{abstract}
Relatively little is known about actual cognitive skills and thinking dispositions of teachers, despite their possible importance. In the current paper we examined two predictions related to rational performance of teachers. First, we expected that more experienced teachers have more rational thinking dispositions, are more cognitively reflective and discount the future less in comparison to novice teachers. Second, we expected that cognitive reflection is related to options involving more patience. 109 novice teachers (undergraduate students) and 55 experienced teachers participated in the study. Thinking dispositions were measured by RationalExperiential Inventory, cognitive reflection was measured by CRT, to measure future discounting we used intertemporal choice tasks and Consideration for Future Consequences questionnaire. We found that teachers differed significantly from undergraduate students in CRT and all subscales of these measures in the expected direction, with the exception of CFC-Immediate and REI-Experiential Engagement, but we found no significant differences between teachers and students (with one exception) on intertemporal choice tasks. The results also confirmed the expected relationships between CRT, CFC and REI. These results pose some important implications for educating future teachers.
\end{abstract}

Key words: cognitive reflection, rational thinking style, consideration for future consequences, teachers, novice vs. expert

"No, no! The adventures first, explanations take such a dreadful time."

Lewis Carroll, Alice's Adventures in Wonderland \& Through the Looking-Glass

This study was supported by the Slovak Research and Development Agency by grant scheme No. APVV-0361-12: Decision Making of Professionals: Processual, Personality and Social Aspects.

Correspondence concerning this paper should be addressed to Marek Jurkovič, Institute of Experimental Psychology, Center of Social and Psychological Sciences, Slovak Academy of Sciences, Dúbravská cesta 9, 84104 Bratislava, Slovak Republic. E-mail: marek.jurkovic@savba.sk.

Received November 13, 2016
When dealing with the issue of rational choices, researchers usually come with a rather bleak picture of human rationality - it seems that in most cases we are unable to consistently pick normatively correct choices. It has been shown that people will exert as little mental effort as possible and only rarely check their intuitive, albeit incorrect responses (Alter, Oppenheimer, Epley, \& Eyre, 2007; De Neys, Rossi, \& Houdé, 2013; Sinayev \& Peters, 2015). One of the solutions would be to teach people skills that would help them solve rational tasks correctly (mindware; Stanovich, 2011) and thus enhance rationality in everyday life. This suggestion seems very reasonable; however, little research has been done on whether teachers themselves possess this kind of mindware, although we often seem to expect from teachers more than is in their human power. 
Teachers are very important in education. According to Hattie (2003), factors related to the teacher account for about $30 \%$ of the variance in a student's achievement. He describes a teacher as a "person who gently closes the classroom door and performs the teaching act - the person who puts into place the end effects of so many policies, who interprets these policies, and who is alone with students during their 15,000 hours of schooling" (Hattie, 2003, p. 2-3). Among the prototypical attributes of expertise in teaching, he lists five that are directly related to the teacher's decision making, planning and rationality. For example, according to Hattie (2003) an expert teacher, due to extensive practice, is able to rely on automatization of cognitive skills and this enables him/ her to free working memory to deal with other more complex characteristics of the situation. Together with deeper representations about teaching and learning, it also makes the teacher better in recognizing sequences of events occurring in the classroom that in some way affect the learning and teaching of a topic. Thus, the teacher can make better predictions and decisions about the next course of events. Large repertoire of various teaching situations helps $\mathrm{him} /$ her to better anticipate, plan, and improvise as required by the situation. Recognizing patterns in these various teaching situations also allows for better decision-making and identification of more or less important decisions. From this brief description it is already clear that what distinguishes an expert teacher from a merely experienced one are the abilities of deeper reflection of the teaching situation, better planning and decision-making. This is in line with findings from studies using expert populations in real life settings (Klein, 1998).

Research in education psychology often concentrates on comparing effectiveness of various teaching styles and personality of teachers, but relatively little is known about actual cognitive skills and thinking disposi- tions of teachers. Thinking dispositions are, however, one of the crucial aspects of rationality with practical consequences. Pennycook, Fugelsang, and Koehler (2015) showed that the mere willingness to engage analytical thinking as means to overcome intuitive "internal feeling" is a significant predictor of real-world behavior and decision making. For example, more analytical thinkers are more skeptical towards religious, paranormal, and conspiracy concepts. The few studies that have been conducted in Slovakia examining critical thinking of highschool teachers show that teachers of secondary schools achieved unsatisfactory results in critical thinking. Compared to their British counterparts, Slovak teachers scored about 23.10 points lower, and the best Slovak respondent reached only the $20^{\text {th }}$ percentile of the British sample (Kosturková, 2013), which is rather an alarming finding. Kosturková (2013) used the Watson-Glasser test of critical thinking in her studies, which is a rather long and difficult measure. Critical thinking can be viewed as one of the aspects of using rationality and low scores of Slovak teachers might reflect a general lack of teaching critical thinking skills in Slovak educational system, in comparison to the British educational system and thus represent an example of the "mindware gap". In addition, one of our previous studies (Čavojová, 2015), using a sample of future teachers, revealed that the intelligence range of our future teachers was surprisingly wide (IQ 65 to 135), and in some tests of cognitive biases we found a floor effect. For example, only 2 students out of 433 solved correctly all four Wason's selection tasks $(M=0.31, \mathrm{MDN}=0, S D=0.67)$ and only $8.8 \%(M=0.75, \mathrm{MDN}=0, S D=0.99)$ of them solved all three tasks from the Cognitive Reflection Test (CRT) by Frederick (2005). Comparing results of pedagogical students in CRT showed that they did worse than students from College of Public service $(M=0.95)$, Economic University $(M=1.21)$, Psychology $(M=1.3)$ 
and Faculty of Mathematics, Physics and Informatics $(M=1.64)$ (Čavojová \& Hanák, 2016). It is, therefore, a major priority to examine rational thinking skills and dispositions of experienced teachers and novice teachers more thoroughly.

One of the most studied facets of rationality is cognitive reflection (Frederick, 2005) - the ability to suppress an intuitive (but incorrect) response and deliberate about the correct answer. It is often considered as prime measure of rationality representing "resistance to miserly processing" and is predictive of many other rationality tasks (Stanovich, 2011; Toplak, West, \& Stanovich, 2011, 2013). Besides its predictive value in rationality tasks, it was shown that the ability to reflect upon one's intuition was related to more patient choices (Frederick, 2005). It seems that cognitive reflection helps individuals suppress impulsive intuitive behavior (choosing smaller reward now) in favor of a more profitable future option. This finding was generally confirmed by studies, which found that more cognitively reflective people tend to choose more profitable future options and they are willing to risk more, particularly when the gamble has a higher expected value (but even when it did not) (Albaity \& Rahman, 2014; Čavojová \& Hanák, 2014; Frederick, 2005; Hardisty \& Weber, 2009; Oechssler, Roider, Schmitz, \& Oechssler, 2009). Oechssler, Roider, and Schmitz (2009) also found that the high CRT group was more likely to choose the alternative that is compatible with risk neutrality. They argue that people with higher cognitive abilities (as reflected by the CRT) might save more and receive higher expected returns, which can lead to their pronounced role in financial markets. On the other hand, Campitelli and Labollita (2010) found no correlation between CRT and intertemporal choice (preference for more patient options), but they found that CRT was positively related to risk taking when the expected value of gains on the gamble was higher than the value of the safe option.

Cognitive reflection has been widely studied, but the majority of studies employed student samples, with few exceptions focusing usually on professionals in financial decisionmaking, such as traders, bankers and investors (Akiyama, Hanaki, \& Ishikawa, 2014; An, Shi, \& Nordvall, 2012; Thoma, White, Panigrahi, Strowger, \& Anderson, 2015). For example, Thoma et al. (2015) found that professional traders had higher CRT score than non-professionals, even after controlling for gender. This can suggest that professionals develop cognitive reflection skills in the course of their professional development. Although the results of Thoma et al. (2015) do not imply that more experienced traders are more rational than less experienced ones, and the difference in CRT could occur by self-selection of more cognitively reflective individuals into the trading profession ${ }^{1}$, some preliminary results using self-reported rationality measures at least suggest that preference for rational engagement with tasks is related to age (Ballová Mikušková, Hanák, \& Čavojová, 2015; Sladek, Bond, \& Phillips, 2010). One can speculate that professional traders can differ from non-traders in numeracy and analytical cognitive style (related to CRT) because people choosing to be traders are more analytic, but the same line of argument is questionable in choosing a teaching profession. As mentioned above, pedagogical students do not belong to the most cognitively reflective participants (Čavojová \& Hanák, 2016), therefore, it is even more important to examine whether this skill can be enhanced by experience.

Results from CRT obtained from these professional samples seem to suggest that at least financial professionals score somewhat higher in CRT than the average (for review of CRT re-

\footnotetext{
${ }^{1}$ We would like to thank the anonymous reviewer for this suggestion.
} 
sults in various cultural samples see Čavojová \& Hanák, 2016). However, besides the abovementioned low performance in critical thinking of Slovak teachers, little is known about their ability in cognitive reflection. Moreover, focusing on cognitive reflection in teachers is especially interesting, because reflecting upon one's own teaching practices and their effectiveness and cognitive patience in responding to demanding situations in school classes are abilities that are highly desirable in teachers. Therefore, we made it our main goal to study cognitive reflection in proficient teachers and to compare experienced teachers with novices (preservice teachers in their college training).

In addition, studying experienced teachers and a sample of undergraduate students (preservice teachers) has a secondary exploratory goal as well. If we define rationality as the ability to take into account long-term consequences, we can see that this ability is largely required from teachers. Teachers have to set long-term goals for themselves and their students (consideration for future consequences), and because they often do not see the outcomes directly, they have to show some patience as far as their expectations are concerned. Moreover, there are still some interesting questions, which were not addressed by previous research. For example, if cognitive reflection is related to more patient options (waiting for future outcomes), how is it related to other personality variables, such as consideration for future consequences (CFC)? Consideration for future consequences, as the ability to suppress immediate rewards and discount the future, is considered among one of the dimensions of rational behavior (Stanovich, 2011). Although $\mathrm{CFC}$ has been recognized as a factor accounting for some individual differences relevant to judgment and decision making (Appelt, Milch, Handgraaf, \& Weber, 2011), how this factor relates to other dimensions of rational behavior is still relatively understudied.
Therefore, it is of special interest to study whether the same underlying construct is behind the ability to suppress immediate rewards, ability to consider future consequences and ability to suppress intuitive (but incorrect and immediate) answers, which is measured by the Cognitive Reflection Test (CRT) (Frederick, 2005). Thus, we want to examine whether more future-oriented people are also more reflective and whether these people would discount future rewards more. And vice versa, whether people low in cognitive reflection will be less patient to wait for future gains and whether this relationship will be mediated by their preference for immediate consequences.

To summarize, the goal of this study is twofold: 1) To compare teachers and students (defined according to years of practice as either experienced or novice) in objective (CRT, ITC) and subjective indicators (REI, CFC) of rationality, and 2) to examine the relationship between time preferences (ITC, CFC) and rationality (CRT, REI). Specifically, we focused on two predictions. First, we expected that more experienced teachers have more rational thinking dispositions (as measured by the REI-R and CFC-F), are more cognitively reflective (CRT) and discount the future less (intertemporal choice tasks), in comparison to novice teachers. Second, we expected that cognitive reflection (CRT) is related to more patient options (CFC-F and intertemporal choice tasks).

\section{Methods}

\section{Participants}

The whole sample consisted of 160 participants (136 female). Mean age was $30.26(S D=$ 13.39). Convenience sampling was the employed method for participant selection.

First group of participants consisted of 109 undergraduate students of various pedagogical departments of the Constantine the Philoso- 
pher University in Nitra (91 female participants). This group represented "novice teachers" (Dreyfus \& Dreyfus, 1986a; Varrella, 2000). Mean age in this group was 22.13 yrs. $(S D=$ 4.90). This group of participants was recruited by their educators.

Second group of participants consisted of 55 teachers (45 female participants) from various levels of educational institutions (pre-school = 2 , primary $=31$, secondary $=30$, tertiary $=2$ ) and of various educational focuses. This group represented mostly "proficient teachers" with more than 4 years of practice (Dreyfus \& Dreyfus, 1986b; Varrella, 2000). Mean age of this group was 46.40 yrs. $(S D=9.70)$. The mean of years spent in practice was $22.07 \mathrm{yrs}$. $(S D=9.54)$. The participants in this group were recruited online and were included in the ballot with a chance to win financial rewards.

\section{Materials}

Cognitive Reflection Test. The CRT (Frederick, 2005) is a simple task measuring our tendency towards miserly processing (or cognitive impulsiveness/laziness in defaulting to the autonomous mind) vs. the ability to postpone our judgment (cognitive reflection). In contrast to classic insight problems, such as the nine-dot problem, it primes an attractive intuitive response - the (incorrect) answer comes to mind easily and the individual has to recognize that it is incorrect and calculate the right answer. In this study we used an expanded CRT with seven tasks (Toplak et al., 2013). The scoring remained the same: correct responses were ascribed 1 . The analysis of internal consistency for CRT-3 and CRT-7 items was also included, although CRT is usually not tested for internal consistency. Nevertheless, CRT-3 showed relatively satisfactory level of internal consistency, as determined by Cronbach's alpha $=.65$ (taking into account that this measure contains only three items), CRT-7 also showed satisfac- tory level of internal consistency, as determined by Cronbach's alpha $=.76$.

Temporal discounting of rewards was measured by exactly the same intertemporal choice tasks (ICT) used by Frederick (2005) in his study. The wording of items is in Table 2 . The items for temporal discounting of rewards include several hypothetical choices between an immediate reward and larger delayed reward (items a-e), immediate reward and a sequence of delayed rewards (items $\mathrm{f}-\mathrm{h}$ ), shorter more immediate massage and longer more delayed massage (item i), and a smaller immediate loss or a larger delayed loss (items $\mathrm{j}-\mathrm{k}$ ). The last item (1) was a choice between longer waiting for a book delivery for a smaller amount of money and shorter waiting for a larger amount of money.

In our study the following scales were used:

Consideration for Future Consequences, a 14-item CFC scale (Joireman, Shaffer, Balliet, \& Strathman, 2012). Most research using the CFC scale has treated it as a uni-dimensional construct. Internal reliability for the overall 14-item scale is high (typically ranging from .80 to .85) with a five-week temporal stability of .72 (Strathman, Gleicher, Boninger, \& Edwards, 1994). However, we followed the recommendations of Joireman et al. (2012) and treated the scale as consisting of the following two dimensions: consideration of immediate consequences (CFC-I) and consideration of future consequences (CFC-F). We used a 6-point scale, where 1 was completely disagree and 6 was completely agree. CFC subscales showed satisfactory levels of internal consistency, as determined by Cronbach's alpha (.78 for CFC-F and .79 for CFC-I).

Rational-Experiential Inventory is a 40-item scale for measuring preference for rational thinking (Pacini \& Epstein, 1999). The REI-R is based on the need for cognition and it measures valuation of intellectual challenges, complex thinking, and logical deliberation. Experiential 
subscale is based on Faith in Intuition scale. Both scales were scored on a 6-point scale ( $1=$ strongly disagree, $6=$ strongly agree). Each subscale is further divided into two subscales. Rationality (REI-R) into Rational Ability (REIRA) subscale (ability to think logically and analytically) and Rational Engagement (REI-RE) subscale (reliance on and enjoyment of thinking in an analytical, logical manner). Experiential subscale is divided into Experiential Ability (REI-EA) subscale (ability with respect to one's intuitive impressions and feelings) and Experiential Engagement (REI-EE) subscale (reliance on and enjoyment of feelings and intuitions in making decisions). REI subscales showed satisfactory levels of internal consistency, as determined by Cronbach's alpha, with exception of the Experiential Ability subscale. (.82 for Ra- tional Ability, .83 for Rational Engagement, .06 for Experiential Ability, .72 for Experiential Engagement). Experiential Ability subscale was excluded from further data analysis, subscale of Rationality that consists of Rational Ability and Rational Engagement subscale also showed high level of internal consistency (Cronbach's $\alpha=.90$ ).

\section{Design and Procedure}

In the sample of students, the materials were presented on-line in fixed order: first they filled in some demographic information (age, gender, major of study, etc.), then they answered two questionnaires unrelated to this study and lastly they received materials in this fixed order: CRT7, intertemporal choice tasks, CFC and REI.

Table 1 Descriptives, differences and effect sizes for group of teachers and pedagogical students

\begin{tabular}{lccccccccc}
\hline & \multicolumn{1}{c}{ Whole sample } & \multicolumn{2}{c}{ Students } & \multicolumn{2}{c}{ Teachers } & \multicolumn{2}{c}{ t-test } & \\
& \multicolumn{1}{c}{$M$} & \multicolumn{1}{c}{$S D$} & \multicolumn{1}{c}{$M$} & \multicolumn{1}{c}{$S D$} & \multicolumn{1}{c}{$M$} & \multicolumn{1}{c}{$S D$} & $t(162)$ & $p$ & Cohen's $d$ \\
\hline CRT-3 & 1.02 & 1.09 & 0.82 & 1.03 & $\mathbf{1 . 4 2}$ & 1.12 & 3.435 & $\mathbf{. 0 0 1}$ & $\mathbf{. 5 4}$ \\
CRT-7 & 2.57 & 2.16 & 2.01 & 1.96 & $\mathbf{3 . 6 7}$ & 2.14 & 4.971 & $\mathbf{. 0 0 1}$ & $\mathbf{. 7 8}$ \\
REI-RE & 39.01 & 7.97 & 36.86 & 7.86 & $\mathbf{4 3 . 2 5}$ & 6.35 & 5.228 & $\mathbf{. 0 0 0}$ & $\mathbf{. 8 2}$ \\
REI-RA & 39.18 & 7.82 & 37.04 & 7.71 & $\mathbf{4 3 . 4 2}$ & 6.17 & 5.336 & $\mathbf{. 0 0 0}$ & $\mathbf{. 8 4}$ \\
REI-EE & 36.46 & 6.38 & 37.02 & 6.56 & 35.34 & 5.89 & -1.593 & .113 & -.25 \\
REI-EA & 35.79 & 3.79 & 35.67 & 4.07 & 36.04 & 3.17 & & & \\
REI-R & 78.18 & 14.72 & 73.90 & 14.46 & $\mathbf{8 6 . 6 7}$ & 11.21 & 5.735 & $\mathbf{. 0 0 0}$ & $\mathbf{. 9 0}$ \\
REI-E & 72.25 & 8.86 & 72.69 & 9.46 & 71.38 & 7.56 & & & \\
CFC-I & 21.62 & 5.90 & 21.98 & 5.88 & 20.91 & 5.94 & -1.100 & .273 & -.17 \\
CFC-F & 29.02 & 5.60 & 28.17 & 5.48 & $\mathbf{3 0 . 6 9}$ & 5.52 & 2.768 & $\mathbf{. 0 0 6}$ & $\mathbf{. 4 4}$ \\
\hline NOtes. CRT & & & & &
\end{tabular}

Notes. CRT-3 = Cognitive Reflection Test (3 original items); CRT-7 = expanded CRT; REI-RE = Rational-Experiential Inventory - Rational Engagement; REI-RA = REI Rational Ability; REI-EE = REI - Experiential Engagement; REI-EA = REI - Experiential Ability; REI-R = REI Rational Style; REI-E = REI Experiential Style; CFC-I = Consideration for Future Consequences - Immediate consequences; CFC-F = CFC - Future consequences. 
In the sample of teachers, participants first intertemporal choice tasks, CFC and REI. Lastly, filled in some demographic data (age, gender, they were asked to indicate whether they were experience, approbation, etc.) and then they interested in being randomly chosen to win 30 received materials in this fixed order: CRT-7, EUR.

Table 2 Test of two proportions for intertemporal behavior

\begin{tabular}{|c|c|c|c|c|c|c|c|}
\hline \multirow{2}{*}{\multicolumn{2}{|c|}{$\begin{array}{l}\text { Item } \\
\text { Time preference }\end{array}$}} & \multicolumn{2}{|c|}{ Teachers } & \multicolumn{2}{|c|}{ Students } & \multirow[t]{2}{*}{$\chi^{2}$} & \multirow{2}{*}{$\begin{array}{l}\text { Stat. } \\
\text { Signif. }\end{array}$} \\
\hline & & & \multirow{2}{*}{$\begin{array}{ll}\% \\
21.8\end{array}$} & \multirow{2}{*}{$\begin{array}{l}n \\
29\end{array}$} & \multirow{2}{*}{$\begin{array}{ll}\% \\
26.6\end{array}$} & & \\
\hline $\mathrm{a}$ & $€ 3400$ this month & & & & & \multirow{2}{*}{.447} & \multirow{2}{*}{.504} \\
\hline & or $€ 3800$ next month & 43 & 78.2 & 80 & 73.4 & & \\
\hline \multirow[t]{2}{*}{$\mathrm{b}$} & $€ 100$ now & 37 & 67.3 & 94 & 86.2 & \multirow{2}{*}{8.181} & \multirow{2}{*}{.004} \\
\hline & or $€ 140$ next year & 18 & 32.7 & 15 & 13.8 & & \\
\hline \multirow[t]{2}{*}{$\mathrm{c}$} & $€ 100$ now & 34 & 61.8 & 68 & 62.4 & \multirow{2}{*}{.944} & \multirow{2}{*}{.538} \\
\hline & or $€ 1100$ in 10 years & 21 & 38.2 & 41 & 37.6 & & \\
\hline \multirow[t]{2}{*}{$\mathrm{d}$} & $€ 9$ now & 34 & 61.8 & 80 & 73.4 & \multirow{2}{*}{2.312} & \multirow{2}{*}{.152} \\
\hline & or $€ 100$ in 10 years & 21 & 38.2 & 29 & 26.6 & & \\
\hline \multirow[t]{2}{*}{$\mathrm{e}$} & $€ 40$ now & 25 & 45.5 & 58 & 54.1 & \multirow{2}{*}{.880} & \multirow{2}{*}{.409} \\
\hline & or $€ 1000$ in 10 years & 30 & 54.5 & 51 & 46.8 & & \\
\hline \multirow[t]{2}{*}{$\mathrm{f}$} & $€ 100$ now & 31 & 56.4 & 71 & 65.1 & \multirow{2}{*}{1.197} & \multirow{2}{*}{.308} \\
\hline & or $€ 20$ every year for 7 years & 24 & 43.6 & 38 & 34.9 & & \\
\hline \multirow[t]{2}{*}{$\mathrm{g}$} & $€ 400$ now & 18 & 32.8 & 40 & 36.7 & \multirow{2}{*}{.252} & \multirow{2}{*}{.730} \\
\hline & or $€ 100$ every year for 10 years & 37 & 67.3 & 69 & 63.3 & & \\
\hline \multirow[t]{2}{*}{$\mathrm{h}$} & $€ 1000$ now & 28 & 50.9 & 54 & 49.5 & \multirow{2}{*}{.027} & \multirow{2}{*}{1.000} \\
\hline & or $€ 100$ every year for 25 years & 27 & 49.1 & 55 & 50.5 & & \\
\hline $\mathrm{i}$ & 30 minute massage in 2 weeks & 45 & 82.0 & 97 & 89.0 & & \\
\hline & $\begin{array}{l}\text { or } 45 \text { minute massage in November } \\
\text { (in } 6 \text { months) }\end{array}$ & 10 & 18.0 & 12 & 11.0 & 1.619 & .229 \\
\hline $\mathrm{j}$ & lose $€ 1000$ this year & 4 & 7.3 & 9 & 8.3 & 010 & 1000 \\
\hline & or lose $€ 2000$ next year & 51 & 92.7 & 100 & 91.7 & (1) & 1.000 \\
\hline $\mathrm{k}$ & have your tooth extracted now & 14 & 25.5 & 39 & 35.8 & & \\
\hline & $\begin{array}{l}\text { or have your tooth extracted in } 2 \\
\text { weeks }\end{array}$ & 41 & 74.5 & 70 & 64.2 & 1.782 & .217 \\
\hline 1 & $\begin{array}{l}\text { pay } € 10 \text { for a book delivered in } 2 \\
\text { weeks }\end{array}$ & 21 & 38.2 & 46 & 42.2 & & \\
\hline & $\begin{array}{l}\text { or pay } € 12.50 \text { for a book delivered } \\
\text { the next day }\end{array}$ & 34 & 61.8 & 63 & 57.8 & .244 & .737 \\
\hline
\end{tabular}




\section{Results}

The descriptives for group of teachers and group of pedagogical students are summarized in Table 1.

Firstly, we examined whether teachers and pedagogical students differed in CRT, CFC and REI. CRT score was divided into CRT-7 score for all tasks and CRT-3 solely for the original three tasks from Frederick (2005). For examining the differences between novice and experienced teachers on CRT-3, CRT-7, CFC subscales and REI subscales we used $t$-tests and the results of these analyses are presented in Table 1. There was homogeneity of variances, as assessed by Levene's test for equality of variances.

In an additional analysis, we calculated Cohen's $d$ for all $t$-test comparisons and we found moderate to large effects (from .435 up to .901) for all previously significant results.

For examining the differences between novice (students) and experienced teachers in intertemporal choice tasks, we compared the group of teachers and the group of students to assess whether there were any differences in intertemporal behavior. To do this, we employed the test of two proportions - chi-square test of homogeneity. The two groups differed significantly only on one item out of twelve. Our results are presented in Table 2.

Secondly, we created two sum scores for items measuring time preference. The first score consisted of all time preference items - even those that did not differ significantly between high and low CRT groups in Frederick (2005). The second sum score consisted of only items that differed significantly between high and low CRT groups in Frederick (2005) - items from $a, b, c$ and $l$ (four items in total)

In the next step, we inspected the data for a possible relationship between CRT-3, CRT-7, $\mathrm{CFC}, \mathrm{REI}$ and sum scores for time preference. To do this, we used a test measuring correlational coefficient. Not all variables were normally distributed, as assessed by Shapiro-Wilk's test $(\mathrm{p}<.05)$, thus we used Kendall's tau to establish possible relationships between variables. We found several significant correlations showing weak to moderate relationships. The results are presented in Table 3.

Table 3 Relationships between time preference scores (total and significant only), CRT, CFC and REI

\begin{tabular}{|c|c|c|c|c|c|c|c|c|c|c|c|}
\hline & & $\begin{array}{l}\text { Time } \\
\text { Total }\end{array}$ & $\begin{array}{l}\text { Time } \\
\text { Sign. }\end{array}$ & $\begin{array}{c}\text { CRT- } \\
3\end{array}$ & $\begin{array}{c}\text { CRT- } \\
7\end{array}$ & $\begin{array}{c}\text { CFC- } \\
\text { I }\end{array}$ & $\begin{array}{c}\text { CFC- } \\
\text { F }\end{array}$ & $\begin{array}{c}\text { REI- } \\
\text { RE }\end{array}$ & $\begin{array}{l}\text { REI- } \\
\text { RA }\end{array}$ & $\begin{array}{c}\text { REI- } \\
\text { EE }\end{array}$ & $\begin{array}{c}\text { REI- } \\
\text { R }\end{array}$ \\
\hline Time Total & $\tau_{\mathrm{b}}$ & $\mathrm{x}$ & $.61^{* * * *}$ & .0 & .10 & -.06 & $.14^{*}$ & .08 & .01 & $-.13^{*}$ & .06 \\
\hline Time Sign. & $\tau_{\mathrm{b}}$ & & $\mathrm{X}$ & -.00 & .03 & -.02 & .03 & .01 & .01 & $-.14^{*}$ & .01 \\
\hline CRT-3 & $\tau_{\mathrm{b}}$ & & & $\mathrm{x}$ & $.79^{* * * *}$ & $-.15^{*}$ & $.19^{* * *}$ & $.24^{* * * *}$ & $.26^{* * * *}$ & -.11 & $.27^{* * * *}$ \\
\hline CRT-7 & $\tau_{\mathrm{b}}$ & & & & $\mathrm{x}$ & $-.12^{*}$ & $.20 * * *$ & $.24^{* * * *}$ & $.27^{* * * *}$ & $-.13^{*}$ & $.27^{* * *}$ \\
\hline CFC-I & $\tau_{\mathrm{b}}$ & & & & & $\mathrm{x}$ & $-.23^{* * * *}$ & $-.18^{* * *}$ & $-.19^{* *}$ & .07 & $-.20^{* * * *}$ \\
\hline CFC-F & $\tau_{\mathrm{b}}$ & & & & & & $\mathrm{x}$ & $.33^{* * * *}$ & $.29^{* * * *}$ & .03 & $.35^{* * * *}$ \\
\hline REI-RE & $\tau_{\mathrm{b}}$ & & & & & & & $\mathrm{X}$ & $.55^{* * *}$ & -.08 & $.79^{* * * *}$ \\
\hline REI-RA & $\tau_{\mathrm{b}}$ & & & & & & & & $\mathrm{x}$ & -.10 & $.78^{* * *}$ \\
\hline REI-EE & $\tau_{\mathrm{b}}$ & & & & & & & & & $\mathrm{x}$ & -.11 \\
\hline REI-R & $\tau_{\mathrm{b}}$ & & & & & & & & & & $\mathrm{x}$ \\
\hline
\end{tabular}




\section{Discussion}

The main goal of our study was to compare experienced teachers with novices (students) in objective indicators of rationality - cognitive reflection and preference for higher future outcomes as well as self-reported preference for rational thinking style and consideration for future consequences. Our first prediction was that professional teachers will come across as more rational than pedagogical students in both objective and subjective rationality measures used. Indeed, this is what we found, with only two exceptions - there was no difference between experienced teachers and novices in consideration of immediate consequences and experiential engagement. We also found some support for our second prediction that cognitive reflection is related to preference for future consideration, although the relationship between cognitive reflection and temporal discounting was less straightforward and generally did not replicate Frederick's (2005) findings. In the following paragraphs we will discuss ambiguous findings in more detail.

First, it is necessary to address the relationship between expertise and age, because our participants differed in this variable as well, beside the level of proficiency in teaching (based on years spent in practice). Age could be understood as a confounding variable, but on the other hand, it is rather difficult to separate changes due to age and due to years in practice using our measured variables, because one cannot gain professional experience without aging. While professional experience is not directly related to expertise, since expertise is something additional that an individual might or might not attain (Phillips, Lappan, Grant, \& Arbaugh, 2009), proficiency is usually understood to be related to amount of time spent in practice and to amount of professional experience (Dreyfus \& Dreyfus, 1986; Varrella, 2000).
In one of the interpretations of the results, Slovak teachers are higher in rationality than pedagogical students ${ }^{2}$, whose rationality might improve with age and with an increase in proficiency. However, our study did not support a causal relationship and it is difficult to determine whether the differences between students and teachers are due to the effect of practice or due to some other unaccounted factor (like different admission tests for current and past pedagogical students). On the other hand, RationalExperiential Inventory depends on self-reporting and thus might not be measuring levels of rationality objectively. Also, the Cognitive Reflection Test might be more closely related to numerical ability than to cognitive reflection (Welsh, Burns, \& Delfabbro, 2013) or at least its results might be heavily skewed by the level of numerical ability of participants. This means that higher CRT scores in teachers, when compared to students, might reflect their higher numerical ability and not a higher cognitive reflection.

We found no significant differences between teachers and students (with one exception) on intertemporal choice tasks, thus, this part of our hypotheses concerning a predicted difference in this variable was not confirmed. It also shows us that proficiency in teaching is probably not related to patience. These results can again be interpreted in two ways. First, teachers do not gain patience with age or with years spent in practice. Second, students that pursue pedagogical career are, perhaps, already patient and are more patient than the general population. The second interpretation seems less probable, considering that majoring in education is usually not desirable in the Slovak Republic, due to low future income, and is usually a second choice after seeking acceptance at other uni-

\footnotetext{
${ }^{2}$ But perhaps still lower in rationality than British teachers (Kosturková, 2013), although this study did not directly compare Slovak sample with British sample.
} 
versity departments. But to resolve this issue, we would have had to include a sample of participants from other disciplines and compare their results with participants from the education department.

The second goal of the study was to examine the relationship between time preferences and rationality, and we expected that cognitive reflection is related to more patient options. We found significant weak to moderate relationships in the expected directions between consideration for future consequences subscales, rational-experiential subscales related to rationality and cognitive reflection scores. These results support the assumption behind the CRT that to be successful in this test, one must suppress intuitive and impulsive responses in favor of cognitively more demanding correct ones, and also indicate that even though the score in CRT might be affected by the level of numerical ability in participants, it probably measures at least some tendency for delaying immediate impulsive responses.

On the other hand, the presented results failed to support our prediction of a relationship between cognitive reflection and intertemporal choice, thus failing to replicate findings of Frederick (2005), who reported differences between high and low cognitive reflection groups on some of the intertemporal choice tasks. This might be related to differently analyzed data we calculated sum score for intertemporal choice items instead of task by task comparison and we also included all participants, not just extreme high and low cognitive reflection cases.

Perhaps surprisingly, Consideration for Future Consequences subscales were not significantly correlated with intertemporal choice scores (with exception of one weak relationship). This might mean that these two measures are not measuring the same preference for delayed gratification. It might also mean that participants failed to reflect their actual ability to delay gratification, because Consideration for
Future Consequences is a self-reporting measure. Or it might mean that Consideration for Future Consequences and Intertemporal Choice Tasks measure two unrelated domains of delay gratification.

We further report upon the results showing that self-reporting measures like Rational-Experiential Inventory or Consideration for Future Consequences correlate to some extent with objective measures of rationality, such as the Cognitive Reflection Test, and correlational coefficients show linear relations in the expected direction, although these relations do not go above $t a u-b$ of 0.3 . We also found weak to moderate relations between Consideration for $\mathrm{Fu}-$ ture Consequences subscales and Rational-Experiential Inventory rational subscales in the expected direction - suboptimal focus on immediate needs and concerns showed negative relationship with Rational-Experiential Inventory rational subscales, while focus on future behavior was positively related to Rational-Experiential Inventory rational subscales. This relationship might have again been partially caused by the fact that both measures were selfreported. In spite of this, we also found significant relations with one of the objective measure that we used - the Cognitive Reflection Test.

Intertemporal choice tasks did not correlate with other measures used (with minor exceptions). One issue with Intertemporal Choice Tasks might be related to the inclusion of only hypothetical choices. As Frederick, Loewenstein, \& O’Donoghue (2002) noted in their reviews of research on discount rates, results might differ between hypothetical and real intertemporal choices. Task $j$ (lose $€ 1000$ this year or lose $€ 2000$ next year) might also be interpreted differently from its assumptions. Is it actually more rational to lose a lesser amount now, when participants (mostly students and teachers with relatively low income) cannot afford to lose any, but they might be able to af- 
ford to lose more money later, because they might have managed to save enough by then?

Future research should further illuminate this area of research and resolve whether Slovak teachers are perhaps more rational in these or other domains of rationality. Our research did not address whether differences in rationality between novices and teachers are due to some effect of professional proficiency and experience with teaching, perhaps future longitudinal or experimental studies could shed some light on the nature of these differences that we found and find a causal relationship between professional teaching experience and rational measures.

Also, of interest might be research conducted with the goal to improve rationality in teachers (e.g., in a form of training or during their university education) and find a way to help them educate their pupils on rationality, because the education in critical thinking and rationality is currently insufficient or completely absent in the Slovak educational system. Teaching critical thinking and rationality might be skills especially useful during this time when websites and various media are filled with pseudoscientific nonsense, disinformation and hoaxes inciting anxiety and hatred.

\section{Conclusion}

We conclude our research with the question whether irrational teachers might be able to teach their students to think and act rationally and how rationality is related to proficiency in teaching. Although we found that teachers were more rational in several objective and subjective measures, the source of the improvement is indeterminate. Very often education in the Slovak Republic is reduced to memorizing of authoritative texts without the emphasis on some kind of critical evaluation of the given information. Thus, it is possible to have students at the third level of education, who pass merely by learning passages thoughtlessly word by word. But this process of thoughtless memorizing starts before the third educational level. It starts at elementary and high-schools, because no one teaches the pupils to think rationally and critically, even their teachers do not expect it from them. The resolution of this issue would be beneficial not just to students and teachers, but to the society as a whole, because educated and rational society is able to fight irrational fears and plan the future for its members based on facts and not superstition.

\section{References}

Akiyama, E., Hanaki, N., \& Ishikawa, R. (2014). How do experienced traders respond to inflows of inexperienced traders? An experimental analysis. Journal of Economic Dynamics and Control, 45(59), 118. https://doi.org/10.1016/j.jedc.2014.05.007

Albaity, M., \& Rahman, M. (2014). Cognitive reflection test and behavioral biases in Malaysia. Judgment and Decision Making, 9(2), 149-151.

Alter, A. L., Oppenheimer, D. M., Epley, N., \& Eyre, R. N. (2007). Overcoming intuition: Metacognitive difficulty activates analytic reasoning. Journal of Experimental Psychology. General, 136(4), 569-576. https://doi.org/10.1037/0096-3445.136.4.569

An, N., Shi, X., \& Nordvall, A. (2012). Cognitive Ability and Psychological Biases - Perspectives from chinese stock indiviodual investors.

Appelt, K. C., Milch, K. F., Handgraaf, M. J. J., \& Weber, E. U. (2011). The Decision Making Individual Differences Inventory and guidelines for the study of individual differences in judgment and decision-making research. Judgement and Decision Making, 6(3), 252-262.

Ballová Mikušková, E., Hanák, R., \& Čavojová, V. (2015). Appropriateness of two inventories measuring intuition (the PID and the REI) for Slovak population. Studia Psychologica, 57(1), 63-82.

Campitelli, G., \& Labollita, M. (2010). Correlations of cognitive reflection with judgments and choices. Judgment and Decision Making, 5(3), 182-191.

Čavojová, V. (2015). Problem with reflective learning is lack of reflective teaching. In ICERI2015 Proceedings (pp. 6521-6528). Seville: 8th International Conference of Education, Research and Innovation. Retrieved from https://library.iated.org/view/ CAVOJOVA2015PRO 
Čavojová, V., \& Hanák, R. (2014). Assessing fluid rationality and its relation to cognitive styles. In $\mathrm{T}$. Ahram, W. Karwowski, \& T. Marek (Eds.), Proceedings of the 5th International Conference on Applied Human Factors and Ergonomics AHFE 2014. Krakow.

Čavojová, V., \& Hanák, R. (2016). Culture's influences on cognitive reflection. In J. Cohn, S. Schatz, H. Freeman, \& D. Combs (Eds.), Modeling sociocultural influences on decision making: Understanding conflict, enabling stability (pp. 85-102). Boca Raton, FL: CRC Group, Taylor \& Francis Group.

De Neys, W., Rossi, S., \& Houdé, O. (2013). Bats, balls, and substitution sensitivity: Cognitive misers are no happy fools. Psychonomic Bulletin \& Review, 20(2), 269-73. https://doi.org/10.3758/s13423013-0384-5

Dreyfus, H. L., \& Dreyfus, S. E. (1986a). Mind over machine. New York: The Free Press. Retrieved from ht tp://www.wewoek.com/load-mind-overmachine.html

Dreyfus, H. L., \& Dreyfus, S. E. (1986b). Mind over machine. New York: The Free Press.

Frederick, S. (2005). Cognitive reflection and decision making. Journal of Economic Perspectives, 19(4), 25-42. https://doi.org/10.1257/08953300577 5196732

Frederick, S., Loewenstein, G., \& O’Donoghue, T. (2002). Time discounting and preference: A critical review. Journal of Economic Literature, Vol. XL, 3351-401. https://doi.org/10.1126/science.151. 3712.867-a

Hardisty, D. J., \& Weber, E. U. (2009). Discounting future green: Money versus the environment. Journal of Experimental Psychology. General, 138(3), 329-340. https://doi.org/10.1037/a0016433

Hattie, J. (2003). Teachers make a difference: What is the research evidence? Building teacher quality. Australian Council for Educational Research Annual Conference on: Building Teacher Quality, 1-17.

Joireman, J., Shaffer, M. J., Balliet, D., \& Strathman, A. (2012). Promotion orientation explains why future-oriented people exercise and eat healthy: Evidence from the two-factor consideration of Future Consequences-14 Scale. Personality and Social Psychology Bulletin, 38(10), 1272-1287. https:// doi.org/10.1177/0146167212449362

Klein, G. (1998). Sources of power: How people make decisions. Cambridge, MA: MIT Press.

Kosturková, M. (2013). Kritické myslenie pedagógov stredných škôl. Pedagogika.sk, 4(4), 283-298.

Oechssler, J. J., Roider, A., \& Schmitz, P. W. (2009). Cognitive abilities and behavioral biases. Journal of Economic Behavior \& Organization, 72(1), 147152. https://doi.org/10.1016/j.jebo.2009.04.018
Oechssler, J., Roider, A., Schmitz, P. W., \& Oechssler, J. (2009). Cognitive abilities and behavioral biases. Journal of Economic Behavior and Organization, 72(1), 147-152. https://doi.org/10.1016/j.jebo.2009. 04.018

Pacini, R., \& Epstein, S. (1999). The relation of rational and experiential information processing styles to personality, basic beliefs, and the ratio-bias phenomenon. Journal of Personality and Social Psychology, 76(6), 972-987.

Pennycook, G., Fugelsang, J. A., \& Koehler, D. J. (2015). Everyday consequences of analytic thinking. Current Directions in Psychological Science, 24(6), 425-432. https://doi.org/10.11770963721 415604610

Phillips, E., Lappan, G., Grant, Y., \& Arbaugh, F. (2009). Development of professional expertise. New Scientist.

Sinayev, A., \& Peters, E. (2015). Cognitive reflection vs. calculation in decision making. Frontiers in Psychology, 6(MAY), 1-16. https://doi.org/10.3389/ fpsyg.2015.00532

Sladek, R. M., Bond, M. J., \& Phillips, P. A. (2010). Age and gender differences in preferences for rational and experiential thinking. Personality and Individual Differences, 49(8), 907-911.

Stanovich, K. E. (2011). Rationality and the reflective mind. New York: Oxford University Press.

Strathman, A., Gleicher, F., Boninger, D. S., \& Edwards, C. S. (1994). The consideration of future consequences: Weighing immediate and distant outcomes of behavior. Journal of Personality and Social Psychology, 66(4), 742-752. https://doi.org/10.1037/ 0022-3514.66.4.742

Thoma, V., White, E., Panigrahi, A., Strowger, V., \& Anderson, I. (2015). Good thinking or gut feeling? Cognitive reflection and intuition in traders, bankers and financial non-experts. Plos One, 10(4), e0123202. https://doi.org/10.1371/journal.pone. 0123202

Toplak, M. E., West, R. F., \& Stanovich, K. E. (2011). The Cognitive Reflection Test as a predictor of performance on heuristics-and-biases tasks. Memory \& Cognition, 39(7), 1275-89. https://doi.org/10.3758/ s13421-011-0104-1

Toplak, M. E., West, R. F., \& Stanovich, K. E. (2013). Assessing miserly information processing: An expansion of the Cognitive Reflection Test. Thinking \& Reasoning, 20(2), 147-168. https://doi.org/ 10.1080/13546783.2013.844729

Varrella, G. F. (2000). Science teachers at the top of their game: What is teacher expertise? The Clearing House: A Journal of Educational Strategies, Issues and Ideas, 74(1), 43-46. https://doi.org/10.1080/ 00098655.2000 .11478639 
Welsh, M. B., Burns, N. R., \& Delfabbro, P. H. (2013). The Cognitive Reflection Test: How much more than numerical ability? 35th Annual Conference of the Cognitive Science Society, 1587-1592. 